\title{
Cervical Artery Dissection, Imaging, Trauma and Causal Inference
}

Can. J. Neurol. Sci. 2003; 30: 302-302

There is little doubt that cervical artery dissection causing stroke is associated with major trauma. ${ }^{1}$ Willis et $\mathrm{al}^{2}$ described several cases of unstable cervical fractures through the transverse foramina, among which $46 \%$ had associated asymptomatic vertebral artery dissection. Dissection is quite probably asymptomatic in many unrecognized posttraumatic cases. Indeed, many patients in the series reported in this issue of the Journal ${ }^{3}$ had suffered major trauma. The implication is that vertebral artery injury may be common while remaining asymptomatic.

What has emerged more vociferously in the recent past is the suggestion that minor trauma can also be associated with vertebral and carotid artery dissection and further, that symptoms may be delayed from the time of the trauma., ${ }^{4}$ Patients have been described with stroke or TIA and cervical artery dissection associated with neck turning, swinging a golf club, in-line skating and other sporting activities, ${ }^{6}$ extension of the neck over a hairdresser's sink, ${ }^{7}$ roller coasters $^{8}$ and therapeutic neck adjustment by chiropractors, physiotherapists or other practitioners. $^{9-12}$ Other techniques such as Shiatsu have been implicated. ${ }^{13}$ Two retrospective studies suggest a significant statistical association between chiropractic neck adjustment and stroke. ${ }^{14,15}$ The issue of "chiropractic stroke" has been covered by the Canadian media, ${ }^{16}$ coroner's inquests have been held in Saskatchewan and Ontario and lawsuits against chiropractors have proliferated.

Despite strong circumstantial reports and opinions, the quality of evidence that minor neck trauma including chiropractic neck adjustment causes vertebral or carotid artery dissection remains weak. A majority of papers are case reports or series only representing the weakest tier of clinical evidence. While these case series lend credence to the temporal association between neck adjustment and dissection, some patients suffer the hallmark neck pain of dissection prior to neck adjustment and seek chiropractic assistance for relief of their neck pain. Neck manipulation may then dislodge a preexisting thrombus. Still, the evidence to support other important factors that lead to causative inference remains modest at best. Because major trauma is clearly associated with dissection, a dose-response relationship may be implied. However, it is unclear whether more frequent episodes of minor trauma might lead to dissection. The statistical magnitude of effect for the association between chiropratic neck adjustment and subsequent stroke, characterised by odds ratios derived from retrospective case-control studies are supportive. ${ }^{14}$ However, retrospective case-control studies are subject to many potential biases allowing for continuing uncertainty.

Most importantly, some patients with spontaneous cervical artery dissection or dissection associated with minor trauma have well-defined abnormalities of connective tissue such as one of the Ehlers-Danlos syndromes, ${ }^{17}$ Marfans syndrome, fibromuscular dysplasia, ${ }^{18}$ osteogenesis imperfecta, ${ }^{19}$ multiple exostosis syndrome, Turner's syndrome ${ }^{20}$ or others. It has been suggested that the ultrastructural appearance of skin connective tissue among patients with dissection is pathological compared to normals. ${ }^{21}$ Similarly, one study observed that aortic root dilatation was more common among patients with spontaneous dissection that controls. ${ }^{22}$ Others have noted clear pathological evidence of pre-existing vessel wall structural abnormalities. ${ }^{23}$ No common single genetic mutations have been uncovered among the majority of dissection patients suggesting that dissection may be a multigene phenotype. ${ }^{24,25}$ Other factors that may predispose to dissection include migraine,${ }^{26}$ the postpartum period $^{27,28}$ and recent upper respiratory tract infection. ${ }^{29,30}$ Despite these associations, a majority of dissections causing stroke are idiopathic.

The low incidence of clinically evident dissection at $3 / 100$ 000 per year $^{31}$ also suggests that a combination of factors may be required. In Rothman's paradigm of causal inference, ${ }^{32}$ a disease occurs only when a necessary cause exists. A necessary cause may be a single factor or composed of multiple component causes. Minor trauma is, therefore, a component cause but not a necessary cause of arterial dissection. A genetic diathesis such as Marfans syndrome or recent upper respiratory tract infection are both possible additional component causes. These component causes summate, probably in a temporally ordered fashion, to a necessary cause and dissection occurs. Major trauma may act as both a component cause and a sole necessary cause. Further prospective evidence is needed to define what factors are and are not component causes and what the interactions among these component causes might be. Meanwhile, physicians must investigate patients with possible dissection comprehensively.

Noninvasive investigations such as CT angiography and MR angiography must be interpreted without reference to the history so that nonspecific irregularities on arterial images are not interpreted as dissection because of the history, but because of intrinsic characteristics on the images that lead to the diagnosis of dissection. Exactly because CTA and MRA lead to both nonspecific arterial findings and lack sensitivity for subtle arterial lesions, formal selective cerebral angiography must be performed more frequently to ensure that the correct diagnosis is made. ${ }^{33,34}$ These characteristics make noninvasive imaging reasonable triage procedures before proceeding to angiography; however, in my opinion, a "negative" CTA or MRA should lead to angiography more frequently, not less. Angiography may be supplemented by high resolution axial MR imaging of the neck searching for evidence of intramural blood products in the relevant artery. ${ }^{35}$

Beaudry and Spence ${ }^{3}$ speculate that many of the symptoms 
associated with the postconcussive syndrome are potentially accounted for by vertebrobasilar ischemia. No convincing evidence is presented to support this assertion. The suggested pathophysiology according to neurovascular anatomy would support a biological mechanism. No evidence in the literature exists describing investigation of patients with postconcussive syndromes with angiography.

These observations do challenge conventional thinking about the common problems of acute and delayed posttraumatic neck pain, vertigo and cognitive changes seen by neurologists and neurosurgeons across Canada. Lateral thinking leading to hypothesis generation is the first step in the scientific method. Are vertebral and carotid artery dissection underrecognized and underinvestigated? Is dissection caused by minor trauma? Are some patients with postconcussive syndrome suffering from unrecognized vertebrobasilar ischemia?

Unfortunately, these questions may not be answerable definitively because of the limitations of current diagnostic technology. Common symptoms such as headache are too nonspecific to justify rapid arterial imaging for all such patients. ${ }^{36}$ Noninvasive angiography using MR or CT is simply not sensitive enough to detect subtle endothelial defects representing minor regions of dissection. Better noninvasive techniques or combinations of techniques are needed. Formal selective angiography would be required and even then, as pointed out by the authors, angiography may have a significant false negative rate compared to histological analysis. Physicians may be reluctant to pursue formal selective angiography when the perceived yield is low and the risks of the procedure may be higher than the chance of making a positive diagnosis of dissection. Because clinically evident dissection is rare, a prospective cohort study could be both prohibitively expensive and logistically difficult. A prospective case-control study would be the most appropriate approach to providing further insight into these questions.

Neurologists and neurosurgeons should consider arterial dissection, search for it with due diligence and in clinical practice, the history must not colour the radiological interpretation of noninvasive arterial imaging. The controversies and hypotheses presented by the authors will only be solved with better data.

Michael D. Hill Calgary, Alberta

\section{REFERENCES}

1. Davis JW, Holbrook TL, Hoyt DB, et al. Blunt carotid artery dissection: incidence, associated injuries, screening, and treatment. J Trauma 1990; 30: 1514-1517.

2. Willis BK, Greiner F, Orrison WW, Benzel EC. The incidence of vertebral artery injury after midcervical spine fracture or subluxation. Neurosurgery 1994; 34: 435-442.

3. Beaudry M, Spence JD. Motor vehicle accidents: the most common cause of traumatic vertebrobasilar ischemia. Can J Neurol Sci 2003; 30: 320-325.

4. Auer RN, Krcek J, Butt JC. Delayed symptoms and death after minor head trauma with occult vertebral artery injury. J Neurol Neurosurg Psych 1994; 57: 500-502.

5. Biousse V, D'Anglejan-Chatillon J, Touboul PJ, Amarenco P, Bousser MG. Time course of symptoms in extracranial carotid artery dissections. Stroke 1995; 26: 235-239.

6. Karnik R, Rothmund T, Bonner G, Valentin A, Reuther G. Inline skating as a possible cause of consecutive bilateral vertebral artery dissection. Acta Neurol Scand 2000; 101: 70-71.

7. Weintraub MI. Beauty parlor stroke syndrome: report of five cases. JAMA1993; 269: 2085-2086.

8. Biousse V, Chabriat H, Amarenco P, Bousser MG. Roller-coaster induced vertebral artery dissection. Lancet 1995; 346: 767.

9. Povisen UJ, Kjaer L, Arlien-Soborg P. Locked-in syndrome following cervical manipulation. Acta Neurol Scand 1987; 76: 486-488.

10. Martienssen J, Nilsson N. Cerebrovascular accidents following upper cervical manipulation: the importance of age, gender and technique. Am J Chiro Med 1989; 2: 160-163.

11. Hufnagel A, Hammers A, Schonle PW, Bohm KD, Leonhardt G. Stroke following chiropractic manipulation of the cervical spine. J Neurol 1999; 246: 683-688.

12. Norris JW, Beletsky V, Nadareishvili ZG. Sudden neck movement and cervical artery dissection. The Canadian Stroke Consortium. CMAJ 2000; 163: 38-40.

13. Tsuboi K, Tsuboi K. Retinal and cerebral artery embolism after "shiatsu" on the neck. Stroke 2001; 32: 2441.

14. Rothwell DM, Bondy SJ, Williams JI. Chiropractic manipulation and stroke: a population-based case-control study. Stroke 2001; 32: 1054-1060.

15. Smith WS, Johnston SC, Skalabrin EJ, et alR. Spinal manipulative therapy is an independent risk factor for vertebral artery dissection. Neurology 2003; 60: 1424-1428.

16. Nichols M. Lethal treatment. Macleans 1998; Sep 21: 70-71.

17. Schievink WI, Limburg M, Oorthuys JW, Fleury P, Pope FM. Cerebrovascular disease in Ehlers-Danlos syndrome type IV. Stroke 1990; 21: 626-632.

18. Schievink WI, Bjornsson J, Piepgras DG. Coexistence of fibromuscular dysplasia and cystic medial necrosis in a patient with Marfan's syndrome and bilateral carotid artery dissections. Stroke 1994; 25: 2492-2496.

19. Hill MD, Czechowsky D, Forsyth P, Perry JR. Heritable bone disease and stroke due to vertebral artery dissection. Cerebrovasc Dis 2001; 12: 73-74.

20. Muscat P, Lidov M, Nahar T, Tuhrim S, Weinberger J. Vertebral artery dissection in Turner's syndrome: diagnosis by magnetic resonance imaging. J Neuroimaging 2001; 11: 50-54.

21. Brandt T, Orberk E, Weber R, et al. Pathogenesis of cervical artery dissections: association with connective tissue abnormalities. Neurology 2001; 57: 24-30.

22. Skljarevski V, Turek M, Hakim AM. Cervical artery dissection is associated with widened aortic root diameter. Can J Neurol Sci 1998; 25: 315-319.

23. Johnson CP, Lawler W, Burns J. Use of histomorphometry in the assessment of fatal vertebral artery dissection. J Clin Pathol 1993; 46: 1000-1003.

24. van den Berg JSP, Limburg M, Kappelle LJ, et al. The role of type III collagen in spontaneous cervical artery dissections. Ann Neurol 1998; 43: 494-498.

25. Kuivaniemi H, Prockop DJ, Wu Y, et al. Exclusion of mutations in the gene for type III collagen (COL3A1) as a common cause of intracranial aneurysms or cervical artery dissections: results from sequence analysis of the coding sequences of type III collagen from 55 unrelated patients. Neurology 1993; 43: 2652-2658.

26. D'Anglejan-Chatillon J, Ribeiro V, Mas JL, Youl BD, Bousser MG. Migraine - a risk factor for dissection of cervical arteries. Headache 1989; 29: 560-561.

27. Gasecki AP, Kwiecinski H, Lyrer PA, Lynch TG, Baxter T. Dissections after childbirth. J Neurol 1999; 246: 712-715.

28. Wiebers DO, Mokri B. Internal carotid artery dissection after childbirth. Stroke 1985; 16: 956-959.

29. Grau AJ, Brandt T, Forsting M, Winter R, Hacke W. Infectionassociated cervical artery dissection. Stroke 1997; 28: 453-455.

30. Guillon B, Berthet K, Benslamia L, et al. Infection and the risk of spontaneous cervical artery dissection: a case-control study. Stroke 2003; 34: e79-81. Epub 2003 Jun 12.

31. Schievink WI, Mokri B, Whisnant JP. Internal carotid artery dissection in a community. Rochester, Minnesota, 1987-1992. Stroke 1993; 24: 1678-1680.

32. Rothman KJ, Greenland S. Causation and causal inference. In: 
THE CANADIAN JOURNAL OF NEUROLOGICAL SCIENCES

Rothman KJ, Greenland. Modern Epidemiology. 2nd ed. Lippincott-Raven Publishers USA. 1998.

33. Auer A, Felber S, Schmidauer C, Waldenberger P, Aichner F. Magnetic resonance angiographic and clinical features of extracranial vertebral artery dissection. J Neurol Neurosurg Psych 1998; 64: 474-481.

34. Rother J, Schwartz A, Rautenberg W, Hennerici M. Magnetic resonance angiography of spontaneous vertebral artery dissection suspected on Doppler ultrasonography. J Neurol 1995; 242: 430436.

35. Leira EC, Bendixen BH, Kardon RH, Adams HPJr. Brief, transient Horner's syndrome can be the hallmark of a carotid artery dissection. Neurology 1998; 50: 289-290.

36. Silbert PL, Mokri B, Schievink WI. Headache and neck pain in spontaneous internal carotid and vertebral artery dissections. Neurology 1995; 45: 1517-1522. 